Bartın Üniversitesi İktisadi ve İdari Bilimler Fakültesi Dergisi, 2020, Cilt 11, Sayı 22

Bartın University Journal of Faculty of Economics and Administrative Sciences, 2020, Volume 11, Issue 22

ISSN: 1309-954X / E-ISSN: 2148-2497

http://iibfdergi.bartin.edu.tr/

http://dergipark.gov.tr/bartiniibf

Araştırma makalesi, Gönderim Tarihi: 20.05.2020; Kabul Tarihi: 28.10.2020

\title{
Özel Sektöre Verilen Kredilerin İnovasyon Üzerindeki Etkisi: Avrupa Birliği Ülkeleri ve Türkiye İçin Bir Uygulama
}

\author{
Dr. Öğr. Üyesi Efe Can KILINÇ \\ Kırıkkale Üniversitesi, İIBF, Ekonometri Bölümü \\ efecankilinc@kku.edu.tr , Orcid ID: 0000-0002-3139-0684 \\ Prof. Dr. Nihat ISSIK \\ Kırıkkale Üniversitesi, İİBF, Ekonometri Bölümü \\ nihatis@ hotmail.com, Orcid ID: 0000-0002-0054-5700 \\ Arş. Gör. Suat Serhat YILMAZ \\ Kırıkkale Üniversitesi, İİBF, Ekonometri Bölümü \\ suatserhatyilmaz@gmail.com, Orcid ID: 0000-0003-2900-0824
}

\section{$\ddot{\mathbf{O z}}$}

$\mathrm{Bu}$ çalışmada, özel sektöre yönelik olarak verilen kredilerin inovasyon üzerindeki etkileri 24 Avrupa Birliği üyesi ülke ve Türkiye bağlamında incelenmektedir. 2001 ve 2017 dönemi yıllık verilerini kapsayan çalışmada; Pedroni Eşbütünleşme Analizi, Granger Nedensellik Analizi, FMOLS ve DOLS tahmincileri kullanılarak değişkenler arasındaki ilişki analiz edilmektedir. Çalışmadan elde edilen bulgular, özel sektöre verilen kredilerdeki artışların inovasyonu arttırdığını göstermektedir. FMOLS tahmin sonuçlarına göre; özel sektöre verilen kredi hacmindeki, eğitim endeksindeki ve Ar-Ge harcamalarındaki \%1'lik artış, patent başvurularını sırasıyla yaklaşık olarak; \%0.17, $\% 0.44$ ve $\% 1.24$ oranında arttırmaktadır. DOLS modeli için bu oranlar aynı sırayla yaklaşık olarak; $\% 0.32, \% 0.54$ ve $\% 0.85$ ' dir.

Anahtar Kelimeler: Özel Sektöre Verilen Krediler, İnovasyon, FMOLS, DOLS, Panel Nedensellik Analizi.

JEL Kodları: G21, O31, C23. 


\title{
The Effect of Domestic Credits to Private Sector on Innovation: An Application on European Union Countries and Turkey
}

\begin{abstract}
In this study, the impact of credits to the private sector on the innovation is examined in the scope of 24 European Union member countries and Turkey. In the study, which covers annual data for the period 2001 and 2017, the relationship between the variables is analyzed using Pedroni Cointegration Analysis, Granger Causality Analysis, FMOLS and DOLS estimators. Findings obtained from the study show that increases in credits to the private sector increase innovation. According to FMOLS estimation results; 1\% increase in credit volume given to the private sector, education index and R\&D expenditures makes patent applications approximately raise by $0.17 \%, 0.44 \%$ and $1.24 \%$ respectively. For the DOLS model, these rates are nearly in the same order; $0.32 \%, 0.54 \%$ and $0.85 \%$.
\end{abstract}

Keywords: Domestic Credits to Private Sector, Innovation, FMOLS, DOLS, Panel Causality Analysis.

JEL Codes: G21, O31, C23.

\section{Giriş}

Küresel planda ortaya çıkan rekabet ve ticaret savaşları üzerinden ülkelerin ekonomik anlamda birbirleri ile yarıştıkları günümüzde, onların üretim kapasitesini arttıran ve uluslararası rekabete karşı daha güçlü hale gelmelerini sağlayan inovasyon faaliyetlerinin önemi de giderek artmaktadır. Bu nedenle, rekabetçi ekonomilerde gerek firmalar gerekse kurumlar inovasyon alanlarına yatırımlarını ve kaynaklarını tahsis etmekte ve bu alanlarda büyük maliyetlere katlanmaktadırlar. Bu süreçte firmalar ve kurumlar, çoğu zaman finansman sıkıntısıyla karşı karşıya kalmakta ve finansal sistemden borçlanmaya yönelmektedirler. Böylece, finansal sistemin ve arac1 kurumların ilgili birimlere yönelik olarak verdiği krediler, gerçekleştirilen inovasyon faaliyetlerinin verimlilik ve çıktı artışına dönüşmesinde kritik öneme sahip olmaktadır (Işık, 2017: 54).

Yeni bir girişimin başlatılmasında olduğu gibi, işletme kurulduktan sonra da finansmana sahip olma ve finansmana erişim sağlama işletmeler için büyük önem arz etmektedir. Bu bağlamda, girişimcilerin finansman kaynakları kendileri ve çevreleri (aile, yakın akrabalar vb.) olabileceği gibi; bazı kamu kurum ve kuruluşları, bankalar, melek yatırımcılar ve risk sermayesi kuruluşları da olabilmektedir. Ülkedeki girişimcilik faaliyetinin arttırılmasında ve sürdürülmesinde gelişmiş bir finansal sisteme ve güvenilir bir yatırım ortamına sahip olmak gerekmektedir. İnovasyonun temel yönlendiricilerinden birisinin girişimciler ve onların faaliyetleri olduğu 

An Application on European Union Countries and Turkey

düşünüldüğünde, girişimcilerin finansman ihtiyaçlarının karşılanması ve gelişmiş finansal kurumlara ve olanaklara sahip olunması önem arz etmektedir.

Verimlilik ve çıktı artışındaki etkileri dikkate alındığında ise; inovasyon faaliyetlerini önemli ölçüde etkileyen bankacılık sisteminin ve daha özelde kredilerin bu faaliyetlere etkisinin araştırılması ve anlaşılması, ülkelerin üretim faaliyetlerinin geliştirilmesi açısından önemli bir husus olarak ön plana çıkmaktadır. $\mathrm{Bu}$ amaçla çalışmada, Avrupa Birliğine üye 24 ülkenin ve Türkiye'nin 2001-2017 yılları arasındaki verileri dikkate alınarak, özel sektöre verilen kredilerin ülkelerin inovasyon faaliyetleri üzerindeki etkisi; Pedroni eşbütünleşme ve Granger nedensellik testleri, Dinamik En Küçük Kareler (Dynamic Ordinary Least Squares - DOLS) ve Düzeltilmiş En Küçük Kareler (Fully Modified Ordinary Least Square - FMOLS) yöntemleri aracılığı ile araştırılmıştır.

İlgili alandaki literatür dikkate alındığında bu çalışma; kapsadığı dönem, ülke grubu ve kullanılan değişkenler açısından diğer çalışmalardan farklılıklar göstermektedir. İnovasyon değişkenini temsilen patent sayısının bağımlı değişken olarak kullanıldığı modellere, bağımsız değişken olarak; özel sektöre verilen krediler, Ar-Ge harcamaları ile beşeri sermayeyi temsilen eğitim endeksi de dâhil edilmiştir. Bu yönüyle çalışmanın literatüre katkı sağlaması beklenmektedir.

\section{Literatür Taraması}

Literatürde inovasyon faaliyetleri üzerinde etkili olan; krediler, vergi teşvikleri, bankacılık sisteminin gelişimi gibi faktörlerin incelendiği birçok çalışma bulunmaktadır. Tablo 1'de çalışmanın temelini oluşturan literatür kaynakları kronolojik sıra ile verilmektedir.

Tablo 1. Literatür Taramas1

\begin{tabular}{|c|c|c|c|c|}
\hline Yazarlar & $\begin{array}{c}\text { Tarih Aralığı } \\
\text { / Frekans }\end{array}$ & $\begin{array}{c}\text { Ülke/ Birim } \\
\text { Sayısı }\end{array}$ & Yöntem & Sonuçlar \\
\hline $\begin{array}{l}\text { Archer vd. } \\
(2020)\end{array}$ & $\begin{array}{l}2005-2013 \\
\text { Altı Aylık }\end{array}$ & $\begin{array}{l}\text { Vietnam } \\
\text { 2500 Kobi }\end{array}$ & $\begin{array}{l}\text { Rassal Etkiler } \\
\text { Probit Modeli }\end{array}$ & $\begin{array}{l}\text { Kredilere yapılan kisitlamalar her } \\
\text { zaman inovasyonu } \\
\text { engellemeyebilir. }\end{array}$ \\
\hline $\begin{array}{l}\text { Giebel ve } \\
\text { Kraft (2020) }\end{array}$ & 2008-2009 & $\begin{array}{l}\text { Almanya, } \\
1465 \text { Firma }\end{array}$ & $\begin{array}{l}\text { İki Aşamalı En } \\
\text { Küçük Kareler } \\
\text { (2AEKK) }\end{array}$ & $\begin{array}{l}\text { Firmalar, kriz dönemlerinde } \\
\text { bankaların kredi arzlarındaki } \\
\text { azalmaya bağlı olarak inovasyon } \\
\text { faaliyetlerini azaltmaktadırlar. }\end{array}$ \\
\hline $\begin{array}{l}\text { Wellalage ve } \\
\text { Locke } \\
(2020)\end{array}$ & $\begin{array}{l}\text { 2013-2014 } \\
\text { Y1llik }\end{array}$ & $\begin{array}{c}43 \text { Ülke } \\
13430 \text { Firma }\end{array}$ & Probit Modeli & $\begin{array}{l}\text { Kredi arzında meydana gelen } \\
\text { genişlemeler, firmalar açısından } \\
\text { bütün inovasyon tipleri üzerinde } \\
\text { olumlu bir etkiye sahiptir. }\end{array}$ \\
\hline $\begin{array}{l}\text { Ding vd. } \\
(2020)\end{array}$ & $1992-2015$ & $\begin{array}{c}30 \text { Ülke } \\
\text { 45325 Firma }\end{array}$ & $\begin{array}{l}\text { Sabit Etkiler } \\
\text { Modeli }\end{array}$ & $\begin{array}{l}\text { Yüksek finansal imkânlar ve } \\
\text { krediler, firmaların inovatif } \\
\text { faaliyetlerinin artmasında } \\
\text { etkilidir. }\end{array}$ \\
\hline
\end{tabular}



Avrupa Birliği Ülkeleri ve Türkiye İçin Bir Uygulama

\begin{tabular}{|c|c|c|c|c|}
\hline Işık (2017) & $\begin{array}{l}\text { 1995-2015 } \\
\text { Yillik }\end{array}$ & G-20 Ülkeleri & Panel DOLS & $\begin{array}{l}\text { Banka kredileri inovasyonu, } \\
\text { inovasyon da büyümeyi uzun } \\
\text { dönemde pozitif yönde } \\
\text { etkilemektedir. }\end{array}$ \\
\hline $\begin{array}{l}\text { Madrid- } \\
\text { Guijarro vd. } \\
(2016)\end{array}$ & 2011-2012 & $\begin{array}{l}\text { İspanya } \\
267 \text { Firma }\end{array}$ & EKK & $\begin{array}{l}\text { Finansman kısıtları, KOBI'lerin } \\
\text { inovasyon } \\
\text { azaltmaktadır. }\end{array}$ \\
\hline $\begin{array}{l}\text { Lööf ve } \\
\text { Nabavi } \\
(2016)\end{array}$ & $\begin{array}{l}\text { 1997-2007 } \\
\text { Y1ll1k }\end{array}$ & $\begin{array}{l}\text { İsveç } \\
\text { 8300 Firma }\end{array}$ & $\begin{array}{l}\text { Negatif Binom } \\
\text { Regresyon }\end{array}$ & $\begin{array}{l}\text { Yüksek teknoloji ihracatı yapan } \\
\text { firmalarda kredi k1sıtları } \\
\text { firmaların inovasyon faaliyetleri } \\
\text { üzerinde negatif etkilidir. Fakat, } \\
\text { bu etki orta ve düşük teknoloji } \\
\text { kullanan ihracat firmaları için } \\
\text { geçerli değildir. }\end{array}$ \\
\hline $\begin{array}{l}\text { García- } \\
\text { Quevedo vd. } \\
(2018)\end{array}$ & $2005-2013$ & $\begin{array}{l}\text { İspanya } \\
4600 \text { Firma }\end{array}$ & Probit Modeli & $\begin{array}{lrr}\text { Finansal k1sitlar firmalarin } \\
\text { inovasyon } \\
\text { etmelerinde önemli role sahiptir. }\end{array}$ \\
\hline $\begin{array}{l}\text { Hsu vd. } \\
(2014)\end{array}$ & $\begin{array}{l}\text { 1976-2006 } \\
\text { Yillik }\end{array}$ & 32 Ülke & $\begin{array}{l}\text { Sabit Etkiler } \\
\text { Modeli }\end{array}$ & $\begin{array}{lr}\text { Daha gelişmiş } & \text { hisse renedi } \\
\text { piyasalarına sahip ülkelerde kredi } \\
\text { piyasalarının } & \text { gelişmesi } \\
\text { inovasyonu caydırmaktadır. }\end{array}$ \\
\hline $\begin{array}{l}\text { Bircan ve } \\
\text { Haas (2014) }\end{array}$ & $\begin{array}{l}\text { 2011-2012 } \\
\text { Y1llik }\end{array}$ & $\begin{array}{c}\text { Rusya } \\
\text { 4220 Firma } \\
\text { 45728 Banka }\end{array}$ & $\begin{array}{c}\text { EKK } \\
2 \mathrm{AEKK}\end{array}$ & $\begin{array}{l}\text { Banka kredilerindeki } r \text { artış } \\
\text { teknolojik gelişmeyi } \quad \text { ve } \\
\text { inovasyonu arttırmada önemli bir } \\
\text { etkendir. }\end{array}$ \\
\hline $\begin{array}{l}\text { Aghion vd. } \\
(2012)\end{array}$ & 1994-2004 & $\begin{array}{c}\text { Fransa } \\
13000 \text { Firma }\end{array}$ & $\begin{array}{l}\text { Panel } \\
\text { Ağırlıklandırılmış } \\
\text { EKK }\end{array}$ & \begin{tabular}{lrr}
\multicolumn{2}{l}{ Firmaların Ar-Ge } & yatırımları, \\
kredi imkânlarının & azaldığ1 \\
dönemlerde & daha & fazla \\
konjonktür yönlü & hareket \\
etmektedir. & & \\
\end{tabular} \\
\hline $\begin{array}{l}\text { Silva ve } \\
\text { Carreira } \\
(2012)\end{array}$ & 1996-2004 & $\begin{array}{l}\text { Portekiz } \\
7079 \text { Firma }\end{array}$ & $\begin{array}{c}\text { EKK- } \\
\text { Nakit Akış Oranı } \\
\text { Analizi }\end{array}$ & $\begin{array}{l}\text { Kredi kısıtları ile inovasyon } \\
\text { faaliyetleri arasında negatif bir } \\
\text { ilişki vardır. }\end{array}$ \\
\hline $\begin{array}{l}\text { Czarnitzki } \\
\text { vd. (2011) }\end{array}$ & $\begin{array}{l}1999 \\
\text { Yili }\end{array}$ & $\begin{array}{l}\text { Kanada/ } \\
\text { 5944 Firma }\end{array}$ & $\begin{array}{c}\text { Anket- } \\
\text { Non-Parametrik } \\
\text { Eşleştirme } \\
\text { Yaklaşımı } \\
\end{array}$ & $\begin{array}{l}\text { Vergi kredileri ilave inovasyon } \\
\text { üretimine yol açmaktadır. }\end{array}$ \\
\hline $\begin{array}{l}\text { Bönte ve } \\
\text { Nielen } \\
(2011)\end{array}$ & $\begin{array}{c}2005 \\
\text { Yili }\end{array}$ & $\begin{array}{l}15 \text { Ülkeden } \\
4119 \text { Firma }\end{array}$ & Probit Modeli & $\begin{array}{lcr}\begin{array}{l}\text { İnovasyon } \\
\text { arasında }\end{array} & \text { ticaret } & \text { kredisi } \\
\text { bulunmuştur. } & & \text { ilişki } \\
\text { butif } & & \\
\end{array}$ \\
\hline $\begin{array}{l}\text { Benfratello } \\
\text { vd. }(2008)\end{array}$ & $\begin{array}{c}\text { 1990’lı } \\
\text { Y1llara } \\
\text { Ait Veriler }\end{array}$ & $\begin{array}{l}13608 \text { Firma } \\
500 \text { Personel }\end{array}$ & $\begin{array}{l}\text { Logit Modeli, } \\
\text { Sistem GMM } \\
\text { Modeli }\end{array}$ & $\begin{array}{l}\text { Bankacılığın gelişimi inovasyon } \\
\text { süreçleri üzerinde zayıf, fakat } \\
\text { olumlu bir etkiye sahiptir. }\end{array}$ \\
\hline
\end{tabular}

Archer vd. (2020) çalışmalarında, Vietnam örneği üzerinden kredilerin KOBI'lerin inovasyon faaliyetleri üzerindeki etkisini incelemişlerdir. Bu süreçte ilgili ülkede 2500 işletmenin, 2015-2013 dönemindeki 6 aylık verilerinden faydalanmışlardır. Rassal Etkiler Probit Modeli kullandıkları analiz sonuçları, kredi kısıtlamalarının ilgili literatürün aksine inovasyon faaliyetleri üzerinde olumsuz bir etki doğurmayabileceğini göstermektedir. 

An Application on European Union Countries and Turkey

Giebel ve Kraft (2020), Almanya örneği üzerinden 2008-2009 döneminde yaşanan Küresel Finansal Kriz ile birlikte kredi arzında meydana gelen daralmanın, firmaların inovasyon faaliyetleri üzerindeki etkisini incelemişlerdir. Bu kapsamda, Almanya'da faaliyet gösteren 1465 firmanın verilerinden yararlanmışlardır. Analiz sonuçları, ilgili dönemde yaşanan negatif kredi arz şoklarının, firmaların inovasyon faaliyetleri üzerinde negatif bir etkiye sahip olduğu yönündedir.

Wellalage ve Locke (2020), 43 ülkede faaliyet gösteren 13430 firmayı baz aldıkları çalışmalarında, KOBİ'lere verilen formal ve informal kredilerdeki değişimlerin ilgili birimlerin inovasyon faaliyetleri üzerindeki etkisini incelemişlerdir. 2013-2014 dönemindeki yıllık verileri kapsayan çalışmalarında Probit yönteminden faydalanmışlardır. Elde edilen bulgular, KOBİ'lere yönelik kredi arzında meydana gelen genişlemelerin, firmalar açısından bütün inovasyon tipleri üzerinde pozitif bir etkiye sahip olduğuna işaret etmektedir.

Ding vd. (2020), 1992-2005 dönemini kapsayan veri setinden faydalanarak, 30 ülkede faaliyet gösteren 45325 firma kapsamında, kredilerin inovasyon üzerindeki etkisini Sabit Etkiler Modeli kullanarak incelemişlerdir. Analiz sonuçları, daha yüksek kredi ve finansal imkânların olduğu piyasalarda faaliyet gösteren firmaların inovatif faaliyetlerinin sayısının ve kalitesinin daha yüksek olduğunu ortaya koymuştur.

García-Quevedo vd. (2018), İspanya için 2005-2013 dönemini kapsayan çalışmalarında, finansal kısıtların firmaların inovasyon faaliyetleri üzerindeki etkisini analiz etmişlerdir. 4600 firmayı örneklem olarak ele alan çalışmada, Tekrarlı-İki Değişkenli Probit Modeli kullanılmıştır. Çalışmanın sonuçları, firmaların karşılaştığı finansal kısıtların inovasyon projelerini iptal etmelerinde önemli bir role sahip olduğunu göstermektedir.

Işık (2017), 1995-2015 arasındaki dönem kapsamında banka kredileri ile inovasyon ve inovasyon ile ekonomik büyüme arasındaki ilişkiyi, G-20 ülkelerinin verileri temelinde panel eşbütünleşme analizi ile incelemektedir. Elde edilen bulgular, özel sektöre yönelik olarak sağlanan banka kredilerinin toplam tutarı ile inovasyon ve ekonomik büyüme oranları ile inovasyon değişkenlerinin eş bütünleşik olduğuna işaret etmektedir. Panel Dinamik En Küçük Kareler (PDOLS) metodu ile araştırılan uzun dönem eş bütünleşme katsayıları, ilgili dönem içinde G-20 ülkeleri kapsamında banka kredileri ile inovasyon arasında uzun dönemli pozitif bir ilişkinin var olduğunu ortaya koymaktadır. Ayrıca çalışma, söz konusu ilişkinin inovasyon ile ekonomik büyüme arasında da olduğuna işaret etmektedir.

Lööf ve Nabavi (2016), İsveç’teki 8300 firma özelinde, kredi kısıtlarının ihracat yapan firmaların inovasyon faaliyetleri üzerindeki etkisini ele almışlardır. 1997-2007 dönemindeki yıllık verileri kapsayan çalışmada, ilgili ilişkinin ölçülmesinde Negatif Binom Regresyon yönteminden faydalanılmıştır. Çalışmanın analizinden elde edilen bulgular; yüksek teknoloji ihracatı yapan firmalarda kredi kısıtlarının firmaların inovasyon faaliyetleri üzerinde negatif etkisinin olduğunu, fakat bu etkinin orta ve düşük teknoloji kullanan ihracat firmaları için geçerli olmadığını göstermektedir. 

Avrupa Birliği Ülkeleri ve Türkiye İçin Bir Uygulama

Madrid-Guijarro vd. (2016), 2011-2012 dönemini kapsayan verilerden faydalanarak, İspanya için finansman kısıtları ile inovasyon faaliyetleri arasındaki ilişkiyi 267 firma özelinde incelemişlerdir. Çalışmanın temel bulgularına göre, finansman kısıtlarının KOBI'lerin inovasyon faaliyetleri üzerinde negatif bir etkisi vardir.

Er vd. (2015), alternatif finansman kaynaklarının girişimcilik açısından bir firsat olduğunu ortaya koymuştur. Bu noktada çalışmada girişimcilere, geleneksel finansal kaynaklara ek olarak alternatif finansal kaynakların kullanımında etkinliğin sağlanması açısından önerilerde bulunulmaktadır.

İçke (2014), Schumpeter'in inovasyonun ortaya konmasında bankacılık sisteminin rolü üzerinde durduğu çalışmasında, Schumpeter'in bankaların kredi yaratma özelliğine değindikten sonra, inovasyonun finansmanına yönelik yaklaşımını ele almıştır. Ardından, insanlığın kıt kaynaklara karşı verdiği savaşta inovasyonları desteklemenin ve inovasyon süreçlerinden yana olmanın insanlığın ekonomik refahı için önem arz ettiğini ortaya koymuştur.

Hsu vd. (2014), finansal gelişmenin teknolojik inovasyonu nasıl etkilediğini incelemektedir. Bu kapsamda, 32 gelişmiş ve gelişmekte olan ülkenin 1976-2006 arası veri seti kullanılarak, sabit etki modeli ile hisse senedi ve kredi piyasalarının gelişiminin teknolojik inovasyonu etkilemesine ilişkin ekonomik mekanizma belirlenmeye çalışılmaktadır. Analiz sonucunda, daha gelişmiş hisse senedi piyasalarına sahip ülkelerde, dış finansmana daha bağımlı ve daha yüksek teknoloji yoğun endüstrilerin orantısız olarak daha yüksek inovasyon düzeyi sergiledikleri bulgusuna ulaşılmıştır. Bununla birlikte, kredi piyasalarının gelişmesinin bu özelliklere sahip endüstrilerde inovasyonu caydırdığg görülmektedir.

Bircan ve Haas (2014), Rusya örneğinden yola çıkarak 2011-2012 dönemi kapsamında 4220 firmanın ve 45728 bankanın verileri aracılığı ile kredilerin inovasyon üzerindeki etkisini EKK ve 2 AEKK yöntemleri kullanarak test etmişlerdir. Elde edilen bulgulara göre, banka kredilerindeki artış teknolojik gelişmeyi ve inovasyonu arttırmaktadır.

Silva ve Carreira (2012), Portekiz için 7079 firmayı kapsayan çalışmalarında, kredi kısıtları ile inovasyon faaliyetleri arasındaki ilişkiyi EKK ve Nakit Akış Oranı Analizlerini kullanarak incelemişlerdir. 1996-2004 yılları arasındaki dönemi kapsayan çalışmada, kredi kısıtları ile inovasyon faaliyetleri arasında negatif bir ilişki olduğu tespit edilmiştir.

Aghion vd. (2012), Fransa'da faaliyet gösteren 13.000 firma üzerinden kredi kısıtlarının firmaların Ar-Ge yatırımları üzerinde etkisini incelemişlerdir. 1994 ve 2004 dönemini kapsayan çalışmada Panel Ağırlıklandırılmış EKK yönteminden yararlanılmıştır. Çalışmanın bulguları, firmaların Ar-Ge yatırımlarının kredi kısıtlarının yoğun olduğu dönemlerde konjonktürel olarak hareket ettiğini göstermektedir. Yine 
çalışma, kredi kısıtlarının olmadığı dönemlerde Ar-Ge yatırımlarının konjonktür karşıtı bir hareket sergilediğini ortaya koymaktadır.

Czarnitzki vd. (2011), Ar-Ge vergi kredilerinin Kanada imalat şirketlerinin inovasyon faaliyetlerine etkisini incelemişlerdir. 1997-1999 döneminde Federal ve İl Ar-Ge vergi kredi programlarının, tüm imalat firmalarının üçte birinden fazlası ve yüksek teknoloji sektörlerindeki firmaların üçte ikisine yakın bir oranı için kullanıldığının belirtildiği çalışmada, parametrik olmayan bir eşleştirme yaklaşımı kullanılarak, Ar-Ge vergi kredilerinin; yeni ürün sayısı, yeni ürünlerle satış, yeniliğin özgünlüğü vb. bir dizi inovasyon göstergesi üzerindeki ortalama etkisi araştırılmaktadır. Elde edilen bulgular, Ar-Ge vergi kredilerinin bulunmadığı varsayımsal bir duruma kıyasla, vergi kredisi alıcılarının, performans göstergelerinin tümünde olmasa da çoğunda önemli ölçüde daha iyi skorlar gösterdiğine işaret etmektedir. Bu nedenle, vergi kredilerinin ilave inovasyon üretimine yol açtığ 1 sonucuna ulaşılmaktadır.

Bönte ve Nielen (2011), ticari krediler ve inovasyon arasındaki ilişkiyi incelemektedir. İnovatif Küçük ve Orta Büyüklükteki İşletmelerin (KOBİ'lerin), kredi kısitlamaları nedeniyle, ticari kredileri inovatif olmayan KOBI'lerden daha fazla kullandığı iddia edilmektedir. Ürün inovasyonu ve ticaret kredisi arasındaki ilişki, 15 Avrupa ülkesinden bir KOBİ örneği kullanılarak ekonometrik olarak incelenmektedir. Analiz sonuçları, inovasyon ve ticaret kredisi arasında pozitif bir ilişki olduğunu doğrulamaktadır. Özellikle, ürün inovasyonu yapan KOBİ'lerin ticaret kredisi kullanma olasılığg diğer KOBİlerden daha yüksektir. Üstelik sonuçlar, ürün inovasyonunun etkisinin, ancak KOBİlerin, finansmana erişimin veya finansman maliyetinin işletmelerinin işletilmesi ve büyümesi için engel olduğunu bildirmesi durumunda, istatistiksel olarak anlamlı olduğunu göstermektedir. Bu nedenle sonuçlar, kredi kısıtı olan inovatif KOBİ'ler için kısa vadeli dış finansman kaynağı olarak ticari kredinin uygunluğuna işaret etmektedir.

Benfratello vd. (2008), 1990'lı yıllara ilişkin çok sayıda İtalyan firması için, inovasyon üzerinde geniş bir veri seti kullanarak, firmaların inovatif faaliyetleri üzerinde yerel bankacılığın gelişiminin etkisini araştırmaktadır. Çalışmada, bankacılığın gelişiminin, özellikle yüksek teknoloji sektöründeki firmalarda, dış finansmana daha bağımlı sektörlerde ve küçük firmalar için, süreç inovasyonu olasılığını etkilediğine dair kanıt elde edilmiştir. Ürün inovasyonuna ilişkin kanıt çok daha zayıftır ve sağlam değildir. Çalışmada aynı zamanda, bankacılığın gelişiminin, özellikle küçük firmalarda, sabit yatırım harcamalarının nakit akışı hassasiyetini azalttığına ve onların Ar-Ge faaliyetlerine başlama olasılığını arttırdığına dair bazı kanıtlara da ulaşılmıştır.

Çalışmaların tamamı incelendiğinde, genel olarak ülkelerin ya da işletmelerin bir şekilde finansman kaynaklarının genişlemesine yol açan; kredi hacminin artması, vergi teşviklerinin artması, bankacılık sisteminin ve hisse senedi piyasasının gelişmesi gibi faktörlerin inovasyon faaliyetleri üzerinde pozitif bir etki oluşturduğu tespit edilmiştir. Bu bağlamda çalışmada, önceki çalışmalardan farklı olarak, Avrupa Birliği ülkeleri ve Türkiye için güncel veriler bağlamında, özel sektöre verilen kredilerin inovasyon 

Avrupa Birliği Ülkeleri ve Türkiye İçin Bir Uygulama

üzerindeki etkileri araştırılmaktadır. Ayrıca çalışma, analizde kullanılan değişkenler bakımından da diğer çalışmalardan farklılaşmaktadır.

\section{Teorik Arka Plan: İnovasyonun Finansmanı}

Latince kökenli olan ve "innovatus" kelimesinden türetilmiş olan inovasyon kelimesi, Türkçede kelime anlamı itibarıyla yenilik, yenilenme ve yenilikçilik gibi anlamlara gelmektedir (Elçi; 2007: 1). Bu noktada, sözlük karşılığı olan yenilik kelimesi inovasyonun tam olarak anlamını karşılayamamaktadır. Çünkü, inovasyon kelimesi ile iktisadi bir değere dönüştürülmüş bir yenilik ifade edilmektedir. Bu anlamda, sadece yeniliklerin ortaya konması inovasyon olarak adlandırılmamakta, aynı zamanda bunların ekonomik bir değere dönüştürülmesi ifade edilmektedir. Joseph Schumpeter inovasyonu, yeni ürünlerin üretilmesi veya yeni ürünlerin üretilmesini yönlendiren faaliyetler olarak tanımlamaktadır. Schumpeter'e göre, bu faaliyetler sonucunda yeni fikirler ve yeni bilgiler, yeni ürün ve hizmetlere dönüştürülmektedir (Saatçioğlu ve Bildirici, 2017: 45).

Finansman kavramı ise, işletmelerin veya firmaların yatırımlarını ve devam eden faaliyetlerini desteklemek için gerekli olan nakit para ya da sermayenin sağlanması olarak tanımlanabilir. İşletmeler genel olarak bu finansman ihtiyacını iki şekilde karşılayabilmektedirler. Bunlar, iç kaynaklı finansman ve dış kaynaklı finansmandır. İç finansman yönteminde şirketlerin ya da firmaların iç kaynakları kullanılmaktadır. Bu kaynaklar, özkaynaklar olarak ifade edilen, işletmeye sahip olanların ve işletmenin ortaklarının mal varlığı ve şirketin faaliyetinden doğan kârları kapsamaktadır. Kurulum aşamasında olan şirketler için iç kaynaklar bu süreçte yeterli olabilirken, gelişme evresine girdiklerinde şirketler dış finansmanın sağlanmasında desteğe ihtiyaç duyabilmektedirler. Başta banka kredileri olmak üzere; girişim sermayesi, faktöring, finansal kiralama, yurt içi ya da yurt dışı kurumlardan veya sermaye piyasalarından sağlanan kaynaklar dış finansman kaynaklarının örnekleridir (Er vd., 2015: 32).

İnovasyon finansmanına gelindiğinde bu kavram; ülkelerin, şirketlerin ya da kurumların çağın son derece hızlı bir şekilde artan rekabet koşullarında ayakta kalabilmek için firma mal ve hizmet üretim yöntemlerini, çağın gerekliliklerine uygun olarak yenilemesi için gerekli olan kaynakların bulunması ve temin edilmesi olarak ifade edilebilir. $\mathrm{Bu}$ noktada ülkeler, kurumlar ve firmalar tarafindan inovasyon uygulamaları ile ulaşılması beklenen en büyük hedef; ortaya çıkan bu inovasyonun toplum açısından; sosyal, ekonomik ve kültürel ihtiyaçlara cevap vermesi, üreticiler açısından ise, onların yeni mal ve hizmet üretimi veya üretim yöntemleri geliştirmek suretiyle firmaların verimliliklerinin arttırılmasıdır (Dam ve Yıldız, 2016: 221). Bu faaliyetler sonucunda elde edilen buluşlar patentlenir ve tescillenirler. Sonrasında, başka alanlarda kullanılarak başka inovasyonların alt basamaklarını oluştururlar. Böylece bu süreç kendi kendini besleyen bir süreci oluşturmaktadır (Işık, 2017: 1).

Günümüzde firmalar zorlu rekabetçi koşullar altında yaratıcı ve inovatif olmak durumunda kalmaktadırlar. Fakat, bu alanlara şirketlerin yatırım yapması büyük 

An Application on European Union Countries and Turkey

maliyetler gerektirmekte, ayrıca büyük risk ve belirsizlikleri de içermektedir (Işıı, 2017: 1). Çünkü inovasyon, yapısından kaynaklanan sebeplerle risk ve belirsizliği içinde barındırmaktadır. Bu risk ile belirsizliklerin doğru ölçümlenmesi ise ilgili inovatif projelerin başarısı açısından önemlidir (Tuna ve İsabetli, 2014: 30).

İnovasyon sürecinde risk faktörünün fazla oluşu, bu faaliyetleri finanse edecek kaynakların bulunmasını da zorlaştırmaktadır. Bu noktada finansal piyasalar, inovasyon faaliyetlerinin finansmanı açısından geniş imkânlar sağlasa bile, bu konuda küresel ölçekte en çok kullanılan kaynaklar kredilerdir (Işık, 2017: 54).

Schumpeter finansal işlemleri ekonomik büyümenin merkezine koymuştur. $\mathrm{Bu}$ noktada Schumpeter finansal işlemler ifadesi yerine bankacı, büyüme terimi yerine ise kalkınma terimini kullanmıştır. Schumpeter'e göre bankacılık sisteminin inovasyon faaliyetlerine sağladığı katkının iki yolla gerçekleştiği söylenebilir:

1- Finansmana ihtiyacı olan girişimcilere finansman sağlamak suretiyle onların inovatif faaliyetlerine yardımcı olmak,

2- Bizzat kendi finansal hizmetlerinde inovasyon yapmak,

Birincisine göre, bankacilar bu noktada yeni kombinasyonlar oluşturarak inovasyon yapmak isteyenler ile üretken araç sahipleri arasında durmaktadır. Bu süreçte bankacılar inovasyon yapmak isteyenlerin yeni kombinasyonlar oluşturmasını olası hale getirmekte ve insanlara yetkiler vererek toplum adına inovasyon yapmalarını sağlamaktadırlar. Ona göre inovasyon, banka kredileri ile birlikte kâr elde edebilmek amacıyla şirketlerin giriştiği ticari bir etkinliktir (Işık, 2017: 54). Bu etkinliğin anlaşılması, kapitalist sistemin nasıl çalıştığını anlamada kritik bir öneme sahiptir. (Aktaran: Sinha (2001: 65), Schumpeter (1934: 78), Schumpeter (1939: 111)).

Schumpeter'in teorisinde bankalar ya da başka bir ifadeyle bankerler, başka girişimcilere finansman sağlayarak inovasyona katkı sağlamalarının ötesinde, bizzat kendi yaptıkları faaliyetlerde inovasyon yapmakta ve finansal hizmetlerin gelişmesine katkı sağlamaktadırlar. Schumpeter'e göre yaratıcı yıkım bankacılık sektöründe de geçerli olmakta; bankaların veya bankerlerin kapitalist sistemde hayatlarını sürdürebilmeleri için onları yaptıkları faaliyetlerde inovasyon yapmaya zorlamaktadır (Festré ve Nasica, 2009: 27).

$\mathrm{Bu}$ çalışmada, Schumpeter'in birinci yaklaşımından yola çıkarak, bankaların firmalara yönelik sağladığı finansman imkânlarından biri olan banka kredilerinin inovasyon faaliyetleri üzerindeki etkileri incelenmektedir.

\section{Veri Seti ve Yöntem}

Bu başlık altında çalışmanın; veri seti, modeli ve yöntemi ele alınmaktadır. 

Avrupa Birliği Ülkeleri ve Türkiye İçin Bir Uygulama

\subsection{Veri Seti}

$\mathrm{Bu}$ çalışmada, 2001-2017 dönemi kapsamında, AB ülkeleri ve Türkiye örneklemi için, özel sektöre verilen yurtiçi kredilerin inovasyon üzerindeki etkileri panel veri yöntemleri olan Pedroni Eşbütünleşme ve Granger Nedensellik Analizi, FMOLS ve DOLS tahmincileri kullanılarak analiz edilmektedir. Bu amaçla, Tablo 2'den de görülebileceği gibi, analizlerde kullanılan değişkenler; patent başvuru sayısı, özel sektöre verilen yurt içi kredilerin hacmi, eğitim endeksi ve Ar-Ge harcamaları olarak belirlenmiştir. Bu noktada, inovasyonu temsil eden değişken olarak Patent başvuru sayısı kullanılmıştır. Tablo 2'de çalışmaya dâhil edilen ülkeler de yer almaktadir.

Tablo 2. Veri Seti ve Ele Alınan Ülkelere İlişkin Açıklamalar

\begin{tabular}{|c|c|c|}
\hline $\begin{array}{c}\text { Değişken } \\
\text { Adları }\end{array}$ & $\begin{array}{c}\text { Değişkenlerin } \\
\text { Kısaltmaları }\end{array}$ & Kapsam \\
\hline $\begin{array}{c}\text { Patent başvuru } \\
\text { sayısı }^{1}\end{array}$ & LNPATENT & $\begin{array}{l}\text { Bir şey yapmanın yeni bir yolunu sağlayan veya bir } \\
\text { soruna yeni bir teknik çözüm sunan bir ürün veya } \\
\text { sürecin özel haklarını almak üzere yerleşikler } \\
\text { tarafindan ulusal patent enstitüsüne yapılan başvuru } \\
\text { sayısıdır. }\end{array}$ \\
\hline $\begin{array}{l}\text { Özel sektöre verilen } \\
\text { yurt içi kredi hacmi }\end{array}$ & LNCV & $\begin{array}{l}\text { Finansal kuruluşlar tarafindan; geri ödemeler için } \\
\text { talepte bulunulan menkul kiymetler, ticari krediler } \\
\text { ve alacaklar gibi özel sektöre verilen finansal } \\
\text { kaynakları temsil eder. Veri, GSYH'ye } \\
\text { oranlanmıstır. }\end{array}$ \\
\hline Eğitim endeksi ${ }^{2}$ & LNEDUC & $\begin{array}{l}\text { Birleşmiş Milletler tarafindan her y1l yayınlanan } \\
\text { İnsani gelişmişlik Endeksi'nin alt endekslerinden } \\
\text { birisidir. Eğitim endeksi, } 25 \text { yaş ve üstü yetişkinler } \\
\text { için y1llarca süren eğitim süresi ve okula giren } \\
\text { çocuklar için beklenen eğitim süresi ile } \\
\text { ölçülmektedir. }\end{array}$ \\
\hline Ar-Ge harcamaları ${ }^{1}$ & LNRD & $\begin{array}{l}\text { İşletme, Devlet, Yükseköğretim ve Özel kâr amacı } \\
\text { gütmeyen kuruluşlardaki sermaye ve cari } \\
\text { harcamaları içerir. Ar-Ge faaliyetleri; temel } \\
\text { araştırma, uygulamalı araştırma ve deneysel } \\
\text { gelişimi kapsar. Veri, GSYH'ye oranlanmıştır. }\end{array}$ \\
\hline \multicolumn{3}{|c|}{$\begin{array}{l}\text { Çalışmaya Dâhil Edilen Ülkeler: Avusturya, Belçika, Bulgaristan, Hırvatistan, Çek } \\
\text { Cumhuriyeti, Danimarka, Estonya, Finlandiya, Fransa, Almanya, Yunanistan, Macaristan, } \\
\text { İrlanda, İtalya, Lüksemburg, Malta, Hollanda, Polonya, Portekiz, Romanya, Slovakya, } \\
\text { Slovenya, İspanya, İsveç ve Türkiye. Güney Kıbrıs Cumhuriyeti, Litvanya ve Letonya veri } \\
\text { eksikliği nedeniyle analiz dışı bırakıllmıştır. }\end{array}$} \\
\hline
\end{tabular}

Kaynak: 1. World Bank, World Development Indicators, https://databank.worldbank.org/home.aspx, 2. United Nations, United Nations Development Programme, Human Development Data (1990-2017), http://hdr.undp.org/en/data Erişim Tarihi: 27.10.2019. 

An Application on European Union Countries and Turkey

\section{2. $\quad$ Model}

Çalışmada özel sektöre verilen yurtiçi kredilerin inovasyon üzerindeki etkilerinin analizinde kullanılan model şu şekildedir:

$\operatorname{LNPATENT}_{i t}=\beta_{0}+\beta_{1} L N R D_{i t}+\beta_{2} L N C V_{i t}+\beta_{3} L N E D U C_{i t}+u_{i t}$

(1) nolu denklemde bağımlı değişken olarak yer alan LNPATENT, kapsamdaki ülkeler için ulusal patent başvuru sayısının doğal logaritmasıdır. $L N R D_{i t}$ değişkeni Ar-Ge harcamalarını, $L N C V_{i t}$ finansal kuruluşlar tarafından özel sektöre sağlanan kredilerin doğal logaritmasını ve $L N E D U C_{i t}$ eğitim endeksinin doğal logaritmasını göstermektedir. $u_{i t}$ ise hata terimini temsil etmektedir.

\subsection{FMOLS ve DOLS Yöntemleri}

Phillips ve Hansen (1990) tarafindan ilk olarak zaman serileri için geliştirilmiş olup, Pedroni (2000) tarafından panel veriye uyarlanmış olan FMOLS tahmincisi, stokastik şoklar ile eşbütünleşik denklem arasında ortaya çıkan uzun dönem korelasyonun neden olabileceği tahmin problemlerine karşı yarı parametrik bir düzeltme metodu kullanmaktadır. Bu nedenle bu tahminci, gerek içsellik dolayısıyla meydana gelen sapmalardan kaçınması, gerekse otokorelasyon düzeltmesi açısından büyük avantajlara sahiptir (Özcan ve Arı, 2014: 49). Asimptotik olarak sapmasız olan ve asimptotik ki-kare istatistiksel çıkarımı kullanan standart Wald testlerine izin veren FMOLS tahmincisi, hata terimlerinin simetrik ve tek taraflı uzun dönemli kovaryans matrislerinin ön tahminlerini kullanmaktadır (Lee ve Brahmasrene, 2014: 100).

FMOLS tahmincisi, OLS tahmincisine içsellik ve seri korelasyon düzeltmeleri yapılarak oluşturulur ve şu şekilde tanımlanır:

$\hat{\beta}_{F M}=\left[\sum_{i=1}^{N} \sum_{t=1}^{T}\left(x_{i t-} \bar{x}_{i}\right)\left(x_{i t-} \bar{x}_{i}\right)^{\prime}\right]^{-1}\left[\sum_{i=1}^{N}\left(\sum_{t=1}^{T}\left(x_{i t-} \bar{x}_{i}\right) \hat{y}_{i t}^{*}+T \hat{\Delta}_{E M}^{*}\right)\right]$

$\hat{y}_{i t}^{*}$, içsellik düzeltilmesinin yapılması amacıyla $y_{i t}$ 'nin dönüştürülmüş değişkenidir. Burada $\hat{y}_{i t}^{*}, \hat{y}_{i t}^{*}=y_{i t}-\widehat{\Omega}_{E M} \widehat{\Omega}_{E M}^{-1} \Delta x_{i t}$ olarak hesaplanmaktadır. Yine $\widehat{\Delta}_{E M}^{*}$ ise serisel korelasyon düzeltme terimidir ve $\widehat{\Delta}_{E M}^{*}=\widehat{\Delta}_{E M}-\widehat{\Delta}_{E} \widehat{\Omega}_{E M}^{-1} \widehat{\Omega}_{E M}$ eşitliği aracılığı ile elde edilmektedir (Dritsaki ve Dritsaki, 2014: 132).

Kao ve Chiang (1997) tarafindan panel veri analizlerine uyarlanan DOLS tahmincisi, bağımsız değişkenlerin birinci farklarının öncülleri ile gecikmelerini bir araya getirmekte, böylece, bağımlı değişkenden bağımsız değişkenlere giden içsel geri besleme etkilerini ortadan kaldırabilmektedir (Çetin vd., 2014: 35). Bu bakımdan, Panel DOLS yöntemiyle elde edilen tahminciler, bağımsız değişkenler ve hata terimleri arasında içsellik problemini gidermesi ve hata terimlerinde otokorelasyon probleminin 

Avrupa Birliği Ülkeleri ve Türkiye İçin Bir Uygulama

üstesinden gelebilmesi açısından Panel OLS tahmincisine kıyasla daha etkindir (Songur ve Yaman, 2013: 535-536). DOLS tahmincisi Stock ve Watson (1993) tahmincisinin genişletilmiş halidir. Panel DOLS tahmincisi aşağıdaki eşitlik yardımıyla elde edilebilir:

$$
y_{i t}=\alpha_{i}+\beta x_{i t}+\sum_{j=q_{1}}^{j=q_{2}} c_{i j} \Delta x_{i, t-j}+V_{i t}
$$

Burada $c_{i j}$ birinci farkı alınmış açıklayıcı değişkenlerin öncül ve gecikmelerinin katsayısıdır. DOLS'nin tahmin edilmiş katsayısı aşağıdaki eşitlikte olduğu gibi ifade edilebilir.

$\hat{\beta}_{D O L S}=\left[\sum_{i=1}^{N} \sum_{t=1}^{T} q_{i t} q_{i t}{ }^{\prime}\right]^{-1}\left[\sum_{i=1}^{N} \sum_{t=1}^{T} q_{i t} \hat{y}_{i t}^{*}\right]$

Burada $\quad q_{i j}, 2(\mathrm{q}+1) \quad \mathrm{x} 1 \quad$ regressörler vektörü olmaktadır. $q_{i j}=\left[x_{i t}-\bar{x}_{i} \Delta x_{i, t-q}, \ldots, \Delta x_{i, t+q}\right]$ (Dritsaki ve Dritsaki, 2014: 132).

\section{Analiz Sonuçları ve Bulgular}

Tablo 3'te değişkenlere ait tanımlayıcı istatistikler bulunmaktadır. Çarpıklık değerine bakıldığında, değişkenlerin tümü negatif değer aldıklarından negatif yönde sola çarpık oldukları, basıklık değerleri açısından ise sadece LNRD değişkeninin basıklık değeri 3'ten küçük olduğundan dağılımının normal dağılıma göre basık, diğer değişkenlerin dağılımının ise normal dağılıma göre dik oldukları ifade edilebilir.

Tablo 3. Tanımlayıcı İstatistikler

\begin{tabular}{|l|c|c|c|c|}
\hline Değişkenler & LNPATENT & LNCV & LNRD & LNEDUC \\
\hline Ortalama & 6.843031 & 4.266190 & 0.268257 & -0.217886 \\
\hline Medyan & 6.826540 & 4.393854 & 0.264355 & -0.202116 \\
\hline Maksimum & 10.81956 & 5.304591 & 1.364514 & -0.060812 \\
\hline Minimum & 1.098612 & -1.682706 & -0.977289 & -0.673345 \\
\hline Std. Sapma & 1.758751 & 0.633426 & 0.607555 & 0.103765 \\
\hline Çarpıklık & -0.243192 & -2.685684 & -0.144073 & -1.461127 \\
\hline Basıklık & 3.738393 & 22.39492 & 2.017119 & 6.486140 \\
\hline Jarque-Bera & 12.70412 & 6581.483 & 17.04760 & 336.2570 \\
\hline Olasılık & 0.001743 & 0.000000 & 0.000199 & 0.000000 \\
\hline Toplam & 2668.782 & 1663.814 & 104.6201 & -84.97556 \\
\hline Hata Kar. Top. & 1203.257 & 156.0781 & 143.5889 & 4.188457 \\
\hline Gözlem & 390 & 390 & 390 & 390 \\
\hline
\end{tabular}


Değişkenler arasındaki korelasyonlar Tablo 4'te sunulmaktadır. Buna göre, LNPATENT değişkeni ile açıklayıcı değişkenler arasında pozitif ve zayıf ilişki bulunmaktadır. Benzer bir şekilde, açıklayıcı değişkenler arasındaki korelasyonlar istatistiksel olarak anlamlı ve pozitiftir. Ayrıca, bu değişkenler arasındaki korelasyonlar zayıftır. Açıklayıcı değişkenler arasındaki korelasyonların zayıf olması olası bir çoklu doğrusal bağlantı sorununun önüne geçilmesini sağlamaktadır.

Tablo 4. Korelasyon Matrisi

\begin{tabular}{|c|c|c|c|c|}
\hline Değişkenler & LNPATENT & LNCV & LNRD & LNEDUC \\
\hline \multirow{3}{*}{ LNPATENT } & 1.000000 & & & \\
\hline & ----- & & & \\
\hline & ----- & & & \\
\hline \multirow{3}{*}{ LNCV } & 0.126153 & 1.000000 & & \\
\hline & 2.504935 & ----- & & \\
\hline & 0.0127 & ----- & & \\
\hline \multirow{3}{*}{ LNRD } & 0.412691 & 0.500461 & 1.000000 & \\
\hline & 8.924504 & 11.38647 & ----- & \\
\hline & 0.0000 & 0.0000 & ----- & \\
\hline \multirow{3}{*}{ LNEDUC } & 0.191328 & 0.365281 & 0.628417 & 1.000000 \\
\hline & 3.839652 & 7.729324 & 15.91304 & ----- \\
\hline & 0.0001 & 0.0000 & 0.0000 & ----- \\
\hline
\end{tabular}

Not: Tabloda; birinci satır korelasyon değerini, ikinci satır t istatistiğini, üçüncü satır ise olasılık değerini göstermektedir.

Panel veri seti ile çalışılırken, paneli oluşturan birimler (bunlar ülkeler, şehirler, firmalar vb. olabilir) arasında, birimleri etkileyen şoklar, finansal ve ticari ilişkiler gibi sebepler nedeniyle, yatay-kesit bağımlılık olabilmektedir. Yatay-kesit bağımlılığın olması durumunda ise kullanılacak ekonometrik teknikler farklılaşmaktadır. Çalışmada birimler arasında yatay-kesit bağımlılığının olup-olmadığı Pesaran Cross DependencyCD (2004) testi kullanılarak araştırılmış ve elde edilen bulgular Tablo 5'te özetlenmiştir. Yatay-kesit bağımsızlığını gösteren sıfır hipotezi altında yapılan CD testi sonuçlarına göre, tüm değişkenler için $\mathrm{H}_{0}$ hipotezi reddedilmektedir. Dolayısıyla, birimler arasında yatay kesit bağımlılı̆̆ı söz konusudur.

Tablo 5. Yatay-Kesit Bağımlılı̆̆ı Testi

\begin{tabular}{|l|c|c|c|c|}
\hline Değişken & CD-test & Olasılık & Corr & abs(corr) \\
\hline LNPATENT & 2.12 & 0.034 & 0.036 & 0.455 \\
\hline LNRD & 20.70 & 0.000 & 0.324 & 0.625 \\
\hline LNCV & 24.97 & 0.000 & 0.384 & 0.599 \\
\hline LNEDUC & 53.41 & 0.000 & 0.817 & 0.825 \\
\hline
\end{tabular}



Avrupa Birliği Ülkeleri ve Türkiye İçin Bir Uygulama

Not: $\mathrm{H}_{0}$ hipotezi yatay kesit bağımsızlığını gösterir. $\mathrm{CD} \sim \mathrm{N}(0,1)$

Çalışmada kullanılan tüm değişkenler için yatay kesit bağımlılı̆̆ı tespit edildiğinden, bu bağımlılı̆̆ı dikkate alan ikinci nesil birim kök testi (Yatay-Kesitsel Olarak Genişletilmiş Im, Pesaran-Shin- Cross-Sectionally Augmented Im, PesaranShin-CIPS, 2007) kullanılarak değişkenlerin durağanlıkları incelenmiştir. Tablo 6'da yer alan sonuçlara göre, serilerin tamamı düzeylerinde birim kök içermekte, birinci farkları alındığında ise durağan duruma gelmektedirler.

Tablo 6. CIPS Birim Kök Testi

\begin{tabular}{|l|c|c|c|c|c|}
\hline \multirow{2}{*}{ Değişken } & \multirow{2}{*}{$\begin{array}{c}\text { Gecikme } \\
\text { Düzeyi }\end{array}$} & \multicolumn{2}{|c|}{ Trendsiz } & \multicolumn{2}{c|}{ Trendli } \\
\cline { 2 - 6 } & $\mathbf{Z t - b a r}$ & Olasılık & Zt-bar & Olasılık \\
\hline \multirow{2}{*}{ LNPATENT } & $\mathbf{0}$ & -0.292 & 0.385 & 0.053 & 0.521 \\
\cline { 2 - 6 } & $\mathbf{1}$ & 1.933 & 0.973 & 1.835 & 0.967 \\
\hline \multirow{2}{*}{ LNRD } & $\mathbf{0}$ & -0.692 & 0.245 & 0.541 & 0.706 \\
\cline { 2 - 6 } & $\mathbf{1}$ & -1.325 & 0.093 & 0.878 & 0.810 \\
\hline \multirow{2}{*}{ LNCV } & $\mathbf{0}$ & 0.627 & 0.735 & -0.129 & 0.449 \\
\cline { 2 - 6 } & $\mathbf{1}$ & 0.383 & 0.649 & 1.017 & 0.845 \\
\hline \multirow{2}{*}{ LNEDUC } & $\mathbf{0}$ & -1.132 & 0.129 & 0.686 & 0.754 \\
\cline { 2 - 6 } & $\mathbf{1}$ & -0.694 & 0.244 & 0.358 & 0.640 \\
\hline \multirow{2}{*}{ LNPATENT } & $\mathbf{0}$ & 379.894 & 0.000 & 328.978 & 0.000 \\
\cline { 2 - 6 } & $\mathbf{1}$ & 192.913 & 0.000 & 152.235 & 0.000 \\
\hline \multirow{2}{*}{ LNRD } & $\mathbf{0}$ & -7.468 & 0.000 & -5.999 & 0.000 \\
\cline { 2 - 6 } & $\mathbf{1}$ & -2.851 & 0.002 & -1.372 & 0.085 \\
\hline \multirow{2}{*}{ LNCV } & $\mathbf{0}$ & -7.052 & 0.000 & -5.648 & 0.000 \\
\cline { 2 - 6 } & $\mathbf{1}$ & -4.390 & 0.000 & -3.625 & 0.000 \\
\hline \multirow{2}{*}{ LNEDUC } & $\mathbf{0}$ & -7.522 & 0.000 & -5.135 & 0.000 \\
\cline { 2 - 6 } & $\mathbf{1}$ & -4.315 & 0.000 & -1.359 & 0.087 \\
\hline
\end{tabular}

Serilerin aynı mertebeden durağan olmaları sebebiyle olası uzun dönem ilişkileri Pedroni eşbütünleşme testi kullanılarak hem sabitli hem de sabitli ve trendli durumlar için ayrı ayrı test edilmiştir. Modelde; hem sabitli hem de sabitli ve trendli durumda kesit-içi (within) etkilerini gösteren dört istatistikten ikisine, kesitler-arası (between) etkileri yansıtan grup istatistiklerinin de iki tanesine göre seriler arasında uzun dönemli ilişki vardır (bkz., Tablo 7).

Tablo 7. Pedroni Eşbütünleşme Testi

\begin{tabular}{|l|c|c|c|c|}
\hline Sabit ve Trend Durumları & \multicolumn{2}{|c|}{ Sabitli } & \multicolumn{2}{c|}{ Sabitli ve Trendli } \\
\hline Panel İstatistikleri & İstatistik & Olasılık & İstatistik & Olasılık \\
\hline Panel $\boldsymbol{v}$ & -1.381172 & 0.9164 & -3.940505 & 1.0000 \\
\hline
\end{tabular}



An Application on European Union Countries and Turkey

\begin{tabular}{|l|c|c|c|c|}
\hline Panel rho & 0.594375 & 0.7239 & 2.920936 & 0.9983 \\
\hline Panel PP & -6.190015 & 0.0000 & -7.688723 & 0.0000 \\
\hline Panel ADF & -6.929484 & 0.0000 & -8.042514 & 0.0000 \\
\hline \multicolumn{4}{|l|}{} \\
\hline Grup İstatistikleri & İstatistik & Olasılık & İstatistik & Olasılık \\
\hline Grup rho & 2.375112 & 0.9912 & 4.400780 & 1.0000 \\
\hline Grup PP & -10.53394 & 0.0000 & -11.13454 & 0.0000 \\
\hline Grup ADF & -8.346629 & 0.0000 & -8.672799 & 0.0000 \\
\hline
\end{tabular}

Not: Gecikme uzunluğu Schwarz Bilgi Kriterine göre otomatik olarak belirlenmiştir.

Değişkenler arasında uzun dönemli bir ilişki tespit ettikten sonra, bu ilişkinin yönü ve derecesi FMOLS ve DOLS tahmincileri kullanılarak araştırılmıştır. Tablo 8'de yer alan bulgulara göre, hem FMOLS hem de DOLS tahmincileri açısından; yurtiçi kredi hacminde, Ar-Ge harcamalarında ve eğitim endeksinde meydana gelen artışlar inovasyonu temsil eden patent başvurusunu arttırmaktadır.

Tablo 8. FMOLS ve DOLS Tahmincileri Bulguları

\begin{tabular}{|l|c|c|}
\hline (Bağımlı Değişken LNPATENT) & DOLS \\
\hline Değişkenler/Tahminciler & FMOLS & $\begin{array}{c}0.318353 * * * \\
(0.069098)\end{array}$ \\
\hline \multirow{2}{*}{ LNCV } & $\begin{array}{c}0.171785^{* * *} \\
(0.019045)\end{array}$ & $\begin{array}{c}0.538804 * * * \\
(0.104018)\end{array}$ \\
\hline \multirow{2}{*}{ LNRD } & $\begin{array}{c}0.440764 * * * \\
(0.020374)\end{array}$ & $\begin{array}{c}0.856311^{* *} \\
(0.385078)\end{array}$ \\
\hline \multirow{2}{*}{ LNEDUC } & $\begin{array}{c}1.239269 * * * \\
(0.013437)\end{array}$ \\
\hline
\end{tabular}

Not: Parantez içindeki katsayılar standart hataları göstermektedir.

***: Katsayı $\% 1$ düzeyinde anlamlıdır. **: Katsayı $\% 5$ düzeyinde anlamlıdır.

FMOLS tahmin sonuçlarına göre; özel sektöre verilen kredi hacmindeki, Ar-Ge harcamalarındaki ve eğitim endeksindeki \%1'lik artış, patent başvurularını sırasıyla yaklaşık olarak; \%0.17, \%0.44 ve \%1.24 oranında arttırmaktadır. DOLS modeli için bu oranlar aynı sırayla yaklaşık olarak; $\% 0.32, \% 0.54$ ve $\% 0.85$ 'dir.

Değişkenler arasındaki nedensellik Granger Nedensellik Analizi kullanılarak araştırılmıştır. Tablo 9'da yer alan bulgulara göre, kredi hacminden patent başvurusuna ve eğitim endeksine doğru tek yönlü, kredi hacmiyle Ar-Ge harcamaları arasında iki yönlü, Ar-Ge harcamaları ile patent başvuruları arasında iki yönlü ilişki bulunmaktadır. Diğer taraftan, patent başvuruları ile eğitim endeksi ve Ar-Ge harcamaları ile eğitim endeksi arasında bir nedensellik yoktur. 
Tablo 9. Granger Nedensellik Testi Bulguları

\begin{tabular}{|l|c|c|c|}
\hline Sıfir Hipotezi & Gözlem & F-İst & Olasılık \\
\hline DLNRD, DLNPATENT'in Granger nedeni değildir. & 297 & 3.56570 & 0.0146 \\
\hline DLNPATENT, DLNRD'nin Granger nedeni değildir. & & 5.63006 & 0.0009 \\
\hline DLNCV, DLNPATENT'in Granger nedeni değildir. & 292 & 7.31663 & 0.0001 \\
\hline DLNPATENT, DLNCV'nin Granger nedeni değildir. & & 0.44596 & 0.7203 \\
\hline DLNEDUC, DLNPATENT'in Granger nedeni değildir. & 303 & 0.54537 & 0.6516 \\
\hline DLNPATENT, DLNEDUC'un Granger nedeni değildir. & & 0.94886 & 0.4173 \\
\hline DLNCV, DLNRD'nin Granger nedeni değildir. & 304 & 6.76213 & 0.0002 \\
\hline DLNRD, DLNCV'nin Granger nedeni değildir. & & 2.39195 & 0.0687 \\
\hline DLNEDUC, DLNRD'nin Granger nedeni değildir. & 318 & 0.22819 & 0.8767 \\
\hline DLNRD, DLNEDUC'un Granger nedeni değildir. & & 1.17975 & 0.3175 \\
\hline DLNEDUC, DLNCV'nin Granger nedeni değildir. & 310 & 1.04836 & 0.3714 \\
\hline DLNCV, DLNEDUC'nin Granger nedeni değildir. & & 5.76932 & 0.0008 \\
\hline
\end{tabular}

Not: Optimal gecikme uzunluğu 3 olarak belirlenmiştir.

AB ülkeleri ve Türkiye kapsamında, özel sektöre verilen yurtiçi kredilerin inovasyon faaliyetleri üzerindeki etkilerinin araştırıldığı bu çalışmanın bulguları; inovasyon ile özel sektör kredileri arasında uzun dönemli bir ilişki olduğunu, özel sektöre verilen kredilerin miktarı arttıkça inovasyon faaliyetini temsil eden patent başvurularının arttığını ve özel sektör kredilerinin, inovasyon faaliyetlerinin Granger nedeni olduğunu göstermektedir. Tahmin sonuçları ayrıca, eğitim endeksindeki ve ArGe harcamalarındaki artışın da inovasyon faaliyeti üzerinde pozitif etkili olduğunu ortaya koymaktadır.

\section{Sonuç ve Değerlendirme}

Teknolojik gelişmelerin hızlı bir şekilde yaşandığı günümüz bilgi çağında; ülkeler, kurumlar ve firmalar açısından bu gelişmelere uyum sağlamak zorunluluk haline gelmiştir. Bu anlamda birçok uluslararası ve ulusal şirket ve firmalar inovasyona ayak uydurabilmek amaciyla inovasyon faaliyetlerine yönelmişlerdir. Fakat bu noktada söz konusu faaliyetlerin finansmanı şirketler açısından bir problem olarak ortaya çıkmakta, bu finansal darboğazın aşılmasında ise krediler kritik bir öneme sahip olmaktadır. Buradan hareketle çalışmada, Avrupa Birliği'ne üye 24 ülkenin ve Türkiye'nin 2001-2017 yılları arasındaki verilerinden faydalanılarak, özel sektöre verilen kredilerin ülkelerin inovasyon faaliyetleri üzerindeki etkisi Pedroni eşbütünleşme ve Granger nedensellik testleri, Dinamik En Küçük Kareler (DOLS) ve Düzeltilmiş En Küçük Kareler (FMOLS) yöntemleri kullanılarak incelenmiştir. 

An Application on European Union Countries and Turkey

Modellerde, bağımlı değişken olarak inovasyonu temsilen ülkelerin patent başvuru sayıları dikkate alınmıştır. Bağımsız değişkenler olarak; özel sektöre verilen yurt içi kredi hacmi ve Ar-Ge harcamaları ve eğitim endeksi değişkenleri kullanılmıştır. Analiz süresince öncelikle değişkenlere ait özet istatistiklerine ve korelasyon matrisine yer verilmiştir. Ardından, ülkeler arasındaki yatay-kesit bağımlılık Pesaran (2004) CD testi kullanılarak araştırılmış ve ilgili birimler arasında yatay-kesit bağımlılığın var olduğu sonucuna ulaşılmıştır. Yatay kesit bağımlılığını dikkate alan ikinci nesil birim kök testi olan Pesaran (2007) CIPS birim kök testi kullanılarak değişkenlerin durağanlıkları incelenmiştir. Birim kök testi sonuçları serilerin tamamının düzeylerinde birim kök içerdiğini, fakat, serilerin birinci farkları alındığında durağan duruma geldiklerini göstermiştir. Serilerin aynı mertebeden durağan olmaları sebebiyle, olası uzun dönem ilişkiler Pedroni eşbütünleşme testi kullanılarak incelenmiş ve modelde kullanılan değişkenler arasında uzun dönem ilişkinin var olduğu tespit edilmiştir. Daha sonra çalışmada, FMOLS ve DOLS tahmincileri aracılığı ile ilgili değişkenlerin inovasyon üzerindeki etkileri araştırılmış; hem FMOLS hem de DOLS tahmincileri açısından, yurtiçi kredi hacminde, Ar-Ge harcamalarında ve eğitim endeksinde meydana gelen artışların inovasyonu temsil eden patent başvurusunu arttırdığı görülmüştür. FMOLS tahmin sonuçlarına göre; özel sektöre verilen kredi hacmindeki, eğitim endeksindeki ve Ar-Ge harcamalarındaki \%1'lik artış, patent başvurularını sırasıyla yaklaşık olarak; \%0.17, \%0.44 ve \%1,24 oranında arttırmaktadır. DOLS modeli için bu oranlar aynı sırayla yaklaşık olarak; \%0.32, \%0.54 ve \%0.85'dir.

Yapılan nedensellik analizine gelindiğinde; elde edilen bulgular, özel sektöre verilen kredi miktarının inovasyon faaliyetini temsil eden patent başvurularının ve beşeri sermayeyi temsil eden eğitim endeksinin Granger nedeni olduğu, kredi hacmiyle Ar-Ge harcamaları arasında iki yönlü, Ar-Ge harcamaları ile patent başvuruları arasında iki yönlü ilişki bulunduğunu göstermiştir. Bununla birlikte, patent başvuruları ile eğitim endeksi ve Ar-Ge harcamaları ile eğitim endeksi arasında ise nedensellik ilişkisine rastlanılmamıştır. Elde edilen bu bulgular, Wellalage ve Locke (2020), Ding vd. (2020), Işık (2017), Madrid-Guijarro vd. (2016), Bircan ve Haas (2014), Silva ve Carreira (2012) Bönte ve Nielen (2011) çalışmalarında elde edilen bulgular ile paralellik arz etmektedir.

Son olarak çalışmanın bulguları, ülkelerde özel sektöre verilen kredi hacminin arttırılmasının, ülkelerin enflasyon hedeflemesi gibi diğer makro-ekonomik hedefleri ile çatışmamak kaydıyla, inovasyon faaliyetlerini desteklemek amacıyla kullanılabileceğini göstermektedir. Çalışmadan elde edilen bu sonuçların, Türkiye gibi gelişmekte olan ülkeler için, geleceğe yönelik olarak yapılacak eylem planlarında politika yapıcılar açısından yol gösterici bir özellikte olduğu düşünülmektedir. 

Avrupa Birliği Ülkeleri ve Türkiye İçin Bir Uygulama

\section{Kaynakça}

Archer, L., Sharma, P., Su, J. (2020). Do Credit Constraints Always Impede Innovation? Empirical Evidence from Vietnamese SMEs, Applied Economics, 117.

Aghion, P., P. Askenazy, N. Berman, G. Cette, and L. Eymard. (2012). Credit Constraints and the Cyclicality of R\&D Investment: Evidence from France. Journal of the European Economic Association, 10 (5), 1001-1024.

Benfratello, L., Schiantarelli, F., ve Sembenelli A. (2008). Banks and Innovation: Microeconometric Evidence on Italian Firms. Journal of Financial Economics, 90, 197-217.

Bircan, Ç. ve De Haas, R. (2013). Bank Lending and Firm Innovation: Evidence from Russia. Journal of Banking and Finance.

Bönte, W. ve Nielen, S. (2011). Product Innovation. Credit Constraints, and Trade Credit: Evidence from a Cross-country Study, Managerial Decision Economics. 32, 413-424.

Czarnitzki, D., Hanel, P., Rosa, J. M. (2011). Evaluating the Impact of R\&D Tax Credits on Innovation: A Microeconometric Study on Canadian Firms. Research Policy, 40, 217-229.

Çetin, M., Doğan, İ. ve Işık, H. (2014). Enerji Tüketiminin Çevre Kirliliği Üzerindeki Etkisi: Bir Panel Veri Analizi. IAAOJ, Social Science, 2(1), 26-40.

Dam, M. M. ve Yıldız, B. (2016). BRICS-TM Ülkelerinde Ar-Ge ve İnovasyonun Ekonomik Büyüme Üzerine Etkisi: Ekonometrik Bir Analiz. Akdeniz Üniversitesi İktisadi ve İdari Bilimler Fakültesi Dergisi. 16(33), 220-236.

Ding, W., Wei, L., Xie, W. (2020). Does Bank Credit Affect Innovation? Evidence from Collateral Law Reform Evidence from Collateral Law Reform (May 26, 2020). SSRN, https://ssrn.com/abstract=3609352.

Dritsaki, C. ve Dritsaki, M. (2014). Causal Relationship Between Energy Consumption, Economic Growth and Co2 Emissions: A Dynamic Panel Data Approach. International Journal of Energy Economics and Policy, 4(2), 125.

Elçi, Ş. (2007). İnovasyon: Kalkınma ve Rekabetin Anahtarı. İnomer, Rekabet ve Kalkınma.

Er, B., Şahin, Y. E. ve Mutlu, M. (2015). Girişimciler İçin Alternatif Finansman Kaynaklar1: Mevcut Durum ve Öneriler. Uluslararass Ekonomi ve Yenilik Dergisi, 1(1), 31-54. 

An Application on European Union Countries and Turkey

Festré, A., Nasica, E. (2009). Schumpeter on money, banking and finance: an institutionalist perspective. The European Journal of the History of Economic Thought, 16(2), 325-356.

Işık, N. (2017). Banka Kredisi, İnovasyon, Ekonomik Büyüme İlişkilerinin Analizi: G-20 Örneği. Bankacılık ve Sermaye Piyasası Araştırmaları Dergisi - BSPAD, $1(2), 53-66$.

İçke, M. A. (2014). Schumpeter ve Yeniliklerin Finansmanı. KSÜ Sosyal Bilimler Dergisi, Nisan 2014, 11(1), 17-38.

García-Quevedo, J., Segarra-Blasco, A., Teruel, M. (2018). Financial Constraints and the Failure of Innovation Projects, Technological Forecasting and Social Change, 127, 127-140.

Giebel, M., Kraft, K. (2020). Bank Credit Supply And Firm Innovation Behavior In The Financial Crisis, Journal of Banking \& Finance, 105961.

Hsu, P., Tian, X. ve Xu, Y. (2014). Financial Development and Innovation: CrossCountry Evidence. Journal of Financial Economics, 112, 116-135.

Kao, C. ve Chiang, M. H. (1997). On the Estimation and Inference of A Cointegrated Regression in Panel Data. Working paper, Department of Economics, Syracuse University.

Lee, J. W. ve Brahmasrene, T. (2014). ICT, CO2 Emissions and Economic Growth: Evidence from A Panel of Asean. Global Economic Review, 43(2), 93-109.

Lööf, H., Nabavi, P. (2016). Innovation and Credit Constraints: Evidence from Swedish Exporting Firms, Economics of Innovation and New Technology, 25(3), 269-282.

Madrid-Guijarro, A., García-Pérez-de-Lema, D., Van Auken, H. (2016). Financing constraints and SME innovation during economic crises. Academia Revista Latinoamericana de Administración.

Özcan, B. ve Arı, A. (2014). Araştırma-Geliştirme Harcamaları ve Ekonomik Büyüme İlişkisi: Panel Veri Analizi. Maliye Dergisi,166, Ocak-Haziran 2014, 39-55.

Pedroni, P. (2000). Fully Modified OLS for Heterogeneous Cointegrated Panels, Advanced in Econometrics, 15, 93-130.

Pesaran, M. H. (2004). General Diagnostic Tests for Cross Section Dependence in Panels, CEsifo Working Paper Series 1229, CESifo Group Munich.

Pesaran, M. H. (2007). A Simple Panel Unit Root Test in the Presence of Cross-Section Dependence. Journal of Applied Econometrics, 22(2), 265-312. 

Avrupa Birliği Ülkeleri ve Türkiye İçin Bir Uygulama

Phillips, P., ve Hansen, B. (1990). Statistical Inference in Instrumental Variables Regression with I(1) Processes. Review of Economic Studies, 57, 99-125.

Saatçioğlu, C., ve Bildirici, Ü. (2017). İnovasyon Göstergeleri Bakımından Türkiye'nin OECD Ülkeleri Arasındaki Yeri: Ekonometrik Bir Uygulama. Işsletme ve İktisat Çalışmaları Dergisi, 5(4), 44-56.

Songur, M. ve Yaman, D. (2013). Avrasya Ülkelerinde Gayri Safi Yurtiçi Hasıla Üzerine Doğrudan Yabancı Yatırımlar ve Diş Ticaret'in Etkisi: Panel Eşbütünleşme Analizi. International Conference On Eurasian Economies 2013, 532-540.

Schumpeter, Joseph. (1934). The Theory of Economic Development. Cambridge, Mass.: Harvard University Press.

Schumpeter, Joseph. (1939). Business Cycles: A Theoretical, Historical, and Statistical Analysis of the Capitalist Process. New York:McGraw-Hill.

Silva, F., Carreira, C. (2012), Do Financial Constraints Threat The Innovation Process? Evidence from Portuguese firms, Economics of Innovation and New Technology, 21(8), 701-736.

Sinha, Tapen (2001). The Role of Financial Intermediation in Economic Growth: Schumpeter Revisited. Economic Theory in the light of Schumpeter's Scientific Heritage, India: Spellbound Publishers.

Stock, J.H. ve Watson, M.W. (1993). A Simple Estimator of Cointegrating Vectors in Higher Order Integrated Systems. Econometrica, 61, 783-820

Tuna, A. K. ve İsabetli, İ. (2014). İnovasyonun Finansmanı ve Risk Sermayesi. İstanbul Üniversitesi İktisat Fakültesi Mecmuası, 64(1), 27-47.

United Nations, United Nations Development Programme, Human Development Data (1990-2017) http://hdr.undp.org/en/data Erişim Tarihi: 27.10.2019.

Wellalage, N. H., Locke, S. (2020). Formal Credit And Innovation: Is There A Uniform Relationship Across Types Of Innovation?, International Review of Economics \& Finance, 70, 1-15.

World Bank, World Development Indicators, https://databank.worldbank.org/home.aspx, Erişim Tarihi: 27.10.2019. 